Studies in Continuing Education

\title{
Knowledge practices and relations in professional education
}

\section{Monika Nerland}

To cite this article: Monika Nerland (2018): Knowledge practices and relations in professional education, Studies in Continuing Education, DOI: 10.1080/0158037X.2018.1447919

To link to this article: https://doi.org/10.1080/0158037X.2018.1447919

$$
\text { 曲 Published online: } 14 \text { Mar } 2018 .
$$

Submit your article to this journal $[\pi$

Q View related articles

View Crossmark data $\nearrow$ 


\title{
Knowledge practices and relations in professional education
}

\author{
Monika Nerland \\ Department of Education, University of Oslo, Oslo, Norway
}

\begin{abstract}
The dynamics of knowledge in society have transformed the conditions of professional work and learning. Professional expertise has become increasingly specialised, and practitioners are challenged to keep up with rapid developments in their fields. At the same time, the complexity of professional work requires the integration of different forms of knowledge and knowing. Against this background, the knowledge settings in which learners engage and the practices and resources these offer are of vital importance. This article addresses professional education as embedded in profession-specific 'machineries of knowledge construction', that is, the set of practices and arrangements through which knowledge and ways of knowing in a profession are generated. It is argued that such machineries span settings in education and work. Examples from research in three professional programmes are used to discuss how students are introduced to epistemic practices and resources in selected knowledge settings. Analytical attention is given to the dynamic interplay between people, practices, knowledge resources and educational arrangements as well as to how connections to work and the epistemic machinery are made. Taking these linkages into account is important for our understanding of what learning entails in different areas of expertise and how this may change over time.
\end{abstract}

\section{ARTICLE HISTORY}

Received 26 February 2018

Accepted 27 February 2018

\section{KEYWORDS}

Professional education; professional learning; epistemic practices; machineries of knowledge construction; education-work relations

\section{Introduction}

The conditions of professional work and learning are currently being transformed in several ways. Traditional forms of professionalism are being challenged as relations between professions, their clients, governments and other stakeholders are changing. Moreover, knowledge is becoming more complex and also contested. These developments have generated new demands on professional expertise as well as questions in need of further research. This article foregrounds knowledge practices and relations as one type of change dynamic that influences professional education and learning. It is based upon a Keynote presentation given at the 3rd International ProPEL Conference in 2017, which had relations between professional education and work in meeting contemporary challenges in professional practices as its main conference theme. This article proposes that analytical attention to the knowledge practices and relations that operate in specific educational settings allows for a better understanding of professional education as 
embedded in profession-specific knowledge dynamics. Such dynamics span settings in education and work, and comprise a set of practices and arrangements through which knowledge and ways of knowing in a profession are generated. These practices and arrangements are not stable - rather, they evolve as the ideas and products of different knowledge-generating activities are circulated and approached in professional practices.

One major change that affects professional learning and demands to expertise is related to the pace of knowledge production and how the products of this process are distributed across organisational and national boundaries. New knowledge, standards and advice are circulated rapidly and can usually be easily accessed online. This has led to a growing richness of resources that can be approached and adapted for local use, which has in turn created new opportunities for learning. At the same time, this richness has engendered new challenges for practitioners regarding how to navigate this multitude of resources and advice. Making generalised knowledge 'actionable' is not straightforward but requires active sense-making and analytical skills (Ludvigsen and Nerland 2014; Markauskaite and Goodyear 2016).

Another change is the increase in the number and diversity of knowledge-generating actors and stakeholders that aspire to influence professional practice. These include scientific and practitioner communities of various kinds as well as technology developers and providers, publishers, government agencies, clearing houses, consensus groups and organised user communities. Knowledge and ways of knowing are therefore generated - and even verified - by a multitude of actors at a variety of different sites (Nerland and Jensen 2014b). The products of their activities are distributed, which has led to what has been termed 'multi-charged knowledge settings' in professional education and work (Knorr Cetina and Reichmann 2015). Such settings characteristically incorporate multiple objectives and purposes simultaneously, which are likely to generate tensions at the level of practice. For instance, knowledge that is distributed within a professional field may include advice generated from controlled scientific experiments, knowledge that has been generated and brought forward by users or other stakeholders or experiential knowledge that has been systematised and generalised within a specific professional community. All of these cannot be easily integrated, and the relative emphasis given to knowledge forms and their impetus for professional action will need to be organised in practice.

In such contexts, the challenges of professional learning go beyond the task of attending to problems of practice and making use of given knowledge sources in productive ways. Professionals today bear extended epistemic responsibilities in the sense that they need to engage in selecting, assessing, integrating and adapting knowledge and advice of various kinds in the on-going development of professional practice. In order to meet these new demands, this article argues that there is a need to understand professional learning as embedded in local and extended knowledge dynamics as well as how these are interlinked. Moreover, when adopting such knowledge dynamics as an analytical frame for understanding learning in practice, there is a need to look across the education-work boundary in conceptualising professional education and learning. Although the practices that are enacted in workplaces and in educational settings are socially situated, they are at the same time linked with practices and communities elsewhere in terms of how knowledge, standards and conventions for good practice are circulated and shared in the profession (Hakkarainen et al. 2004; Nerland and Jensen 2014a). 
The article proceeds as follows: It begins by raising some questions about how the education-work relationship is dealt with in prevalent analytical approaches to studying professional learning, especially in educational settings. This leads to a suggestion to expand the analytical frame to account for the dynamic knowledge relations that emerge between actors and sites in a professional knowledge culture. Next, an analytical frame is proposed that conceptualises professional learning as embedded within local and extended machineries of knowledge construction. Thereafter, examples from recent studies on professional learning in higher professional education are presented and discussed to illustrate how knowledge practices and resources link educational activities with knowledge dynamics in the profession. The article concludes by discussing emerging challenges to professional education in expanded knowledge contexts and by suggesting some avenues for future research and the challenges these might entail.

\section{Professional learning and education-work relations}

Perspectives on learning as intrinsic to social practices, and the constitutive role of mediating tools and artefacts in this respect, have obtained a dominant position in research on professional learning. This includes the seminal work on situated learning from the 1990s (Lave 1993; Lave and Wenger 1991), contributions rooted in cultural psychology and cultural-historical activity theory (Billett, Smith, and Barker 2005; Engeström 2004; Engeström and Sannino 2010; Säljö 2010) as well as other practice-based approaches (e.g. Hager, Lee, and Reich 2012). This 'turn to practice' has generated a range of important insights for professional education and learning. Among these are the importance of access to participation in the practices of a community in increasingly advanced ways, the significance of social interaction with mediational means for shared meaningmaking and changes in practice to occur and the way inter-professional collaborations and the development of what has been called 'horizontal expertise' can be fostered in object-oriented work within or across activity systems.

By highlighting practices as the locales in which learning emerges, research in these traditions has contributed significantly to a better understanding of the structures and enactment of social activities as well as their interplay in learning processes. Where the relations between education and work is concerned, research has created awareness about the need for educational programmes to better relate to the complex and often messy work practices for which they aim to prepare their graduates. Moreover, it has generated awareness of how the practices in which students participate are constitutive for learning and of how these take on distinct forms in different organisational contexts. At the same time, one may ask whether the focus on situated practices and on the local instantiations of activity systems might have contributed to the polarisation of education and work as different contexts for learning. This is a consequence of the chosen units and focus of analysis as much as of the conceptual frameworks per se. For instance, in studies that approach professional education and professional work as different activity systems with different objects, tools, rules and division of labour, or in studies that place analytical focus on how 'doing education' and 'doing professional practice' may play out as competing logics in an educational setting, it is the differences in objectives and social organisation between the contexts that are foregrounded. The education-work relationship in professional learning is then considered a boundary that students need to overcome by way of boundary 
crossing and transitioning between two different activity systems or contexts rather than as settings that are embedded in a joint, profession-specific knowledge system that serves professional expertise (see, for instance, Anagnostopoulos, Smith, and Basmadjian 2007).

It is by no means the intention of this article to question the contributions of this research. Studies that have addressed education-work relations in this way have surely led to important insights and repeatedly reminded educational actors and institutions about the limitations of campus-based education in preparing its graduates for 'real' professional practices and the need for establishing productive collaborations between education and work organisations. Nevertheless, what has been given less attention to is how knowledge is circulated and practices are shared across these contexts and serve to constitute learning opportunities both in education and in continued, work-based learning (see also, Lahn and Jensen 2006). To account for such relations one may pay analytical attention to the way learning is related to affordances in the professional expert culture and its knowledge arrangements, rather than to the organisational contexts in which learning takes place. Relevant questions to ask include: What makes it possible to recognise professional practices across sites in the expert culture? How are knowledge and ways of knowing shared and developed across these sites? What kind of artefacts, tools and infrastructures mediate this knowledge sharing? And what characterises collective ways of envisioning knowledge and responsibilities in a profession? These questions open the gates to understanding professional education as interlinked with other sites of knowledge generation in the professional field. Analytically, they require an expansion of the units of analysis where knowledge dynamics and relations are concerned. In the words of Knorr Cetina (1999), there is a need to 'magnify the space for knowledge in action' in order to trace the connections between different knowledge settings and to understand the structural layer of practice and its regulative forces as not only historically developed but as simultaneously emerging at different sites in professional culture and their mutual interplay.

In recent years, several initiatives have been undertaken to expand the units of analysis of professional learning and to investigate it across the education-work boundary. ${ }^{1}$ Sociomaterial approaches have drawn attention to the material, non-human and more-thanhuman elements of practice and paved the way for attending to how materiality acts and exerts effect on emerging practices in ways that link with other sites (Fenwick, Edwards, and Sawchuk 2011). Related to this is the emergence of network analyses inspired by Actor-Network Theory, in which researchers have focused on tracing networks of knowledge and practices that exert influence in different educational settings, rather than taking the individual's engagement as their starting point (Fenwick and Edwards 2013; Nespor 1994). These approaches are sensitive to how material tools and practices enacted in professional education are interlinked with wider networks of knowledge. Hakkarainen et al. (2004) share this interest in knowledge networks but adopt artefact-mediated practices as the starting point for developing a perspective on professional learning as knowledge creation within 'communities of networked expertise'. Other contributions took work practices as a point of departure to trace knowledge relations, such as Malcolm (2014) who used the notions of knowledge practices and object relations from Knorr Cetina $(2001,2007)$ to bring attention to how knowledge 'migrates' across organisational and geographical boundaries in the software location industry. A slightly different contribution is the notion of professional expertise as trans-situated (Nicolini et al. 2017). This notion builds further on the situated learning strand of research but 
conceptualises professional work as accomplished through a set of situated actions in different knowledge settings, which together makes practice possible.

The argument that follows connects to this line of contributions and ways of thinking but focuses specifically on the epistemic aspects of professional education and learning. From a starting point where professions are understood as constituted by a set of knowledge practices and arrangements that are performed in different settings, the next section suggests a conceptual framework for investigating knowledge relations in professional education and how educational practices become linked with profession-specific knowledge dynamics. This should however not be understood as an attempt to 'cover it all' there are certainly many more dimensions and relations beyond the epistemic that are relevant to professional learning. Even still, by magnifying knowledge relations as constitutive of the evolving formation of professional practices and communities, it is an attempt to better grasp these dimensions as spanning sites in education and work.

\section{Professional education as embedded in machineries of knowledge construction}

As an overarching framework, professions can be understood as being constituted of distinct ways of generating and sharing knowledge. This distinctiveness relates to a set of tools, instruments and institutional arrangements as well as to the specific strategies, visions and procedures that guide collective action. Together, these arrangements and mechanisms form the 'machinery of knowledge construction', which, in a given expert culture, 'make up how we know what we know' (Knorr Cetina 1999, 1). Such machineries comprise a range of actors, sites and production contexts in a given field of expertise. For instance, in a profession, they may include knowledge-generating activities in work settings, research activities, clearing houses, consensus groups as well as activities part of educational programmes that all come together to define and engender professional expertise (Nerland and Jensen 2014a). As such, they go beyond organisational boundaries and span settings in education and work. The products generated in the various settings may be circulated, be picked up for exploration and used elsewhere and may thereby serve to link different knowledge settings.

As the concept of machineries indicates, fields of expertise are not stable but are continually reproduced and reconstructed through the ways in which knowledge is approached and enacted in various settings. To understand how knowledge and its related strategies for action relate across knowledge settings in a profession, one may turn to the concept of 'epistemic objects'. Expert communities are typically objectcentred in the sense that they are oriented towards exploring, developing and mobilising knowledge objects (Knorr Cetina 2001). However, such objects are not understood as separate, material things. Instead, they may be described as complex amalgams of material and symbolic resources that constitute knowledge about a problem and, through their inherent complexity, create a set of opportunities when the objects are approached (Nerland and Jensen 2012). Moreover, following Knorr Cetina's (2001) definition, epistemic objects are characterised by their unfolding and question-generating character. In the context of professional learning, epistemic objects could be models for medical treatment, computer programmes, legal texts and complex representations of financial markets. Such objects are created in expert cultures and are further developed by people in different 
settings attending to the objects, exploring their complexity and materialising their potential in local activities. Epistemic objects can be approached at different sites in a profession, be it in education or work. For instance, when looking at what students and professional practitioners explore in their everyday practices, we might find the same medical procedures or advanced technological tools at play in both educational and work settings, although the way the practitioners relate to them may differ. One example is how similar professional knowledge resources and objects are approached by students in software engineering education and software professionals alike, although their learning contexts differ (see Nerland and Damsa in press). For students in professional education, engagement with epistemic objects forms an access point to their evolving expert culture and its collective ways of knowing. Moreover, the objects may stimulate learning as they are explored, further developed and temporarily stabilised in local practices.

The concept of 'epistemic practices' draws attention to specific ways in which knowledge and epistemic objects are approached, generated and shared in a given culture (Knorr Cetina 2007). These involve the collective practices of examining and verifying knowledge or of finding solutions to problems. Epistemic practices also embody the methodological principles and ways of working that are distinctive to a given expert culture, and they are thus fundamental to the procedural aspect of professional expertise. To rephrase Kelly (2011), they can be defined as socially accomplished ways in which members of a profession communicate, assess and legitimatise knowledge claims. Epistemic practices are the means through which objects are explored, refined and further circulated in a profession. Different forms and representations of knowledge require different epistemic practices in order to be 'opened up' to scrutiny or use. Hence, epistemic practices play a critical role in making knowledge 'actionable' and in making expert performance transparent for learners (Jensen, Nerland, and Enqvist-Jensen 2015; Markauskaite and Goodyear 2016).

Seen together, these concepts form a conceptual framework suitable for exploring professional education as embedded in knowledge dynamics that operate within - but extend beyond - local activities. This framework also provides a means to understand professions as being continuously performed into existence through the exploration of shared epistemic objects and the enactment of shared practices in various knowledge settings. The concepts of epistemic objects and practices serve as access points for empirical investigations that may help trace connections to the wider machineries. At the same time, machineries of knowledge construction cannot be studied by 'zooming in' on a single analytical site alone. To map the machineries and their dynamics more comprehensively, analyses need to account for how knowledge and practice are dispersed across a variety of sites in which learners come to participate in multiple ways and the processes and products of different activities become interlinked in complex machineries of knowledge construction. For this article, however, the further discussion will be limited to the question of how these analytical concepts can be used to explore professional learning in educational settings.

\section{Examples from empirical studies in higher professional education}

This section presents examples from empirical studies in higher professional education in Norway, in which epistemic practices and object relations were used as analytical concepts 
to investigate how students become 'enrolled' in profession-specific and evolving machineries of knowledge construction. The term enrolment has been derived from network theories and denotes the ways in which knowledge resources, collective practices and modes of participation work together to lead newcomers into a professional knowledge domain (Nespor 1994). The project from which the examples have been drawn focused included in-depth studies of educational activities in three programmes for teacher education, legal education and software engineering education, conducted in higher education institutions in Norway. ${ }^{2}$ These programmes were selected because of their differences in knowledge dynamics and ways of developing professional practices and because they all emphasised inquiry-oriented activities as a way of introducing students to the collective ways of exploring and working with knowledge in their respective professions. The overall research question that guided the research was, 'what characterises the epistemic machineries at play in educational activities and their mechanisms of enrolment?' To examine this question, the analyses focused on two aspects of the educational activities - how students participated in epistemic practices and were engaged in exploring epistemic objects, and how these epistemic practices and objects served to link the educational activities with the wider epistemic machinery in the profession.

The project included observation-based studies in the introductory courses of the programmes as well as in a later course of each programme that focused on methodological aspects of students' knowledge construction. The empirical material was generated through videotaped observations of teacher-led sessions and students' group work, interviews with teachers and student groups and by collecting course documents of various kinds, knowledge resources and tools utilised in the activities as well as the products generated through the students' work. Special attention was given to the knowledge resources and practices in which students engaged, and to what extent and how these provided linkages to the profession-specific epistemic machineries. The findings of the project have been previously reported elsewhere (see, Damşa, Nerland, and Jensen 2017; Damşa and Nerland 2016; Jensen, Nerland, and Enqvist-Jensen 2015). The discussion that follows will draw on the findings only of the studies conducted in the first semester introductory courses and use these to illustrate the overall theme of professional education as embedded in wider machineries of knowledge construction. The introductory courses are chosen for illustrations because activities in these courses are designed to introduce students to profession-specific ways of 'doing knowledge' as well as to their prospective field of expertise. Hence, they are concerned with key problems and resources that are seen as crucial in the given profession.

All three programmes used inquiry-based activities to introduce the students to their professional knowledge domains. All the introductory courses also used group work wherein students were required to explore problems and construct knowledge together. Groups of four-six students were asked to analyse professional problems and to collaboratively construct a product or well-argued solution based on a joint introduction to an aspect of professional knowledge and its related epistemic resources. The tasks given to students in legal education and teacher education focused on case analyses, while students in software engineering education were asked to develop a webpage. The activities were differently organised in time: as an intensive one-week course with daily, teacher-led sessions and group work in legal education, and as a group process spread across several weeks in teacher education and engineering education. 
Table 1. Characteristics of the three introductory courses.

\begin{tabular}{|c|c|c|c|c|}
\hline & Inquiry task & Epistemic practices & Knowledge resources & $\begin{array}{c}\text { Transformative } \\
\text { means }\end{array}$ \\
\hline $\begin{array}{l}\text { Legal } \\
\text { education }\end{array}$ & $\begin{array}{l}\text { Identifying and resolving } \\
\text { legal conflicts in a case } \\
\text { narrative about a young } \\
\text { couple, their economic } \\
\text { transactions and } \\
\text { consumer rights }\end{array}$ & $\begin{array}{l}\text { Sorting the case to } \\
\text { identify legal } \\
\text { conflicts; } \\
\text { Investigating how } \\
\text { different sources } \\
\text { of law can inform } \\
\text { the case; } \\
\text { Justifying decisions } \\
\text { by building a } \\
\text { convincing legal } \\
\text { argument }\end{array}$ & $\begin{array}{l}\text { Sources of law: } \\
\text { Statutes; } \\
\text { Case book; } \\
\text { Textbooks; } \\
\text { Their own sense of justice }\end{array}$ & $\begin{array}{l}\begin{array}{l}\text { Methodological } \\
\text { principles }\end{array} \\
\rightarrow \frac{\text { Learning to see }}{\frac{\text { the world }}{\text { through the }}} \\
\text { lenses of law }\end{array}$ \\
\hline $\begin{array}{l}\text { Teacher } \\
\text { education }\end{array}$ & $\begin{array}{l}\text { Analysing a narrative about } \\
\text { a pupil in a school who is } \\
\text { treated differently by two } \\
\text { of his teachers by } \\
\text { applying learning theories }\end{array}$ & $\begin{array}{l}\text { Formulating an } \\
\text { inquiry question; } \\
\text { Connecting abstract } \\
\text { concepts and } \\
\text { theories of } \\
\text { learning to the } \\
\text { case; } \\
\text { Academic writing }\end{array}$ & $\begin{array}{l}\text { Textbook; } \\
\text { Lecture notes; } \\
\text { Personal experience }\end{array}$ & $\begin{array}{l}\text { Conceptual } \\
\text { knowledge } \\
\rightarrow \quad \frac{\text { Envisioning }}{\text { oneself in the }} \\
\frac{\text { teacher's role }}{\text { teacher }}\end{array}$ \\
\hline $\begin{array}{l}\text { Software } \\
\text { engineering } \\
\text { education }\end{array}$ & $\begin{array}{l}\text { Developing a webpage } \\
\text { using programming } \\
\text { languages and tools } \\
\text { learned in the course } \\
\text { Writing a project report }\end{array}$ & $\begin{array}{l}\text { Writing, testing and } \\
\text { validating code in } \\
\text { an iterative } \\
\text { manner; } \\
\text { Generating ideas and } \\
\text { justifying choices; } \\
\text { Documenting work }\end{array}$ & $\begin{array}{l}\text { Programming languages; } \\
\text { Standardised } \\
\text { procedures; Validation } \\
\text { tools; Patterns of code; } \\
\text { Github; } \\
\text { Project management tools }\end{array}$ & $\begin{array}{l}\text { Programming tools } \\
\rightarrow \frac{\text { Adopting }}{\frac{\text { systematic }}{\text { programming }}} \\
\underline{\text { strategies }}\end{array}$ \\
\hline
\end{tabular}

Sources: Based on Jensen, Nerland, and Enqvist-Jensen 2015; Damşa and Nerland 2016; Damşa, Nerland, and Jensen 2017.

By using the notion of professional machineries of knowledge construction and the various types of epistemic objects and epistemic practices they involve as an analytical framework, the analyses revealed the types of professional problems students were introduced to and the epistemic practices and resources mobilised through their work. This also served as a basis for examining the transformative means at play in the enrolment process and what kind of transformation the enrolment process entailed in the students' modes of engagement. Table 1 summarises the main features of the three courses with regard to educational arrangements, their epistemic practices and resources as well as their enrolment mechanisms. Text in italics denotes epistemic practices enacted by the students in exploring and resolving their tasks as well as the way in which knowledge forms served as means of transformation. Underlined text denotes the kind of transformation underscored in the enrolment process.

\section{Epistemic practices and object relations}

As presented in Table 1, all three courses introduced students to a set of epistemic practices that were critical to investigative processes in the professional cultures. However, what these practices were about and what kinds of knowledge were mobilised through their enactment varied across the three cases. In legal education, the epistemic practices were closely related to methodological principles in the profession, that is, the rules and conventions for exploring judicial cases and finding or justifying solutions. These practices 
were mediated by legal texts and sources, wherein statutes and court decisions generated in the professional field played a key role. The students' inquiry activities were sequenced in a successive way and often modelled by the teacher, with the students approaching one source of law at a time (Jensen, Nerland, and Enqvist-Jensen 2015). This structure served to keep the epistemic object inherent to the case narrative unfolding throughout the students' inquiry process.

In teacher education, the epistemic practices were oriented towards knowledge integration and were more similar to academic forms of work, through the emphasis on formulating a question for exploration and conducting a theory-led investigation of information included in the case narrative, which eventually needed to be communicated in a written report. Emphasis was placed on the use of theoretical concepts to analyse an imaginary professional situation and on academic writing (Damşa and Nerland 2016). How these epistemic practices should be enacted was however less clear to the students. The knowledge resources mobilised in their work included pedagogical theories and experiences from schooling, but procedural knowledge that could guide the students in how to integrate these contributions was by and large lacking. This generated some challenges in exploring and constructing solutions to the case. Moreover, one could argue that the task in this course reflected educational concerns rather than introducing students to enacting the professional practice of teaching. At the same time, the educational arrangements in the teacher education course channelled professional knowledge through the students' personal experiences of schooling. This represented an interesting point of difference compared to the legal education course, in which the epistemic practices served to create a distance between the students' previous experiences and their emerging legal practices (see also, Damşa, Nerland, and Jensen 2017; Jensen, Nerland, and EnqvistJensen 2015).

In software engineering education, the epistemic practices were closely related to software programming in terms of writing, testing and validating code. This included identifying, assessing and imitating relevant coding patterns that were distributed online by professional programmers as well as the use of standards and tools for validating code (Damşa and Nerland 2016). In addition, the students engaged in generating ideas for their web development task and in documenting their work process to make their choices transparent and justified in a final report. These processes were however mediated by profession-specific tools and standards for coding. The webpage in-the-making served as an unfolding epistemic object that generated new questions and avenues for exploration as solutions to other problems were (temporarily) achieved.

In sum, the problems the students worked on took on the form of complex problemknowledge constellations that could be explored in multiple ways and that generated arenas for knowledge integration and learning. The practices also generated knowledge construction that manifested in the students' responses and product development. The local assemblages of resources and practices were nevertheless differently composed, placing more emphasis on procedural knowledge in legal education and software engineering education and on conceptual understanding in teacher education. How, then, are these educational arrangements linked with wider knowledge dynamics in the three professions? 


\section{Connections to professional machineries of knowledge construction}

Analyses of the three course settings illustrate how students are introduced to profession-specific epistemic practices that operate within, yet stretch beyond, local educational settings. Interpretations of legal statutes, learning theories and programming tools circulate in the professional machineries of knowledge construction and are further explored and utilised in educational settings. The interplay between epistemic practices and the knowledge sources mobilised is important for the kinds of connections that are made. As noted by Bueger (2015), epistemic practices have the capacity to assemble, translate and represent, all of which were visible in the three course settings. For instance, the practices enacted in legal education and software engineering education served to assemble resources from the professional domain and to translate the concepts, principles or procedures into ways of addressing the local problem at hand. The practices and arrangements in these courses were characterised by the extensive use of knowledge resources that circulate in the wider professional community and that are also used by professionals in professional settings. Through engagement with these resources, the students were introduced to other knowledge-generating actors and settings and their roles in the wider machinery. Especially in the legal education course, such roles and functions were made explicit in the teachers' instructions. Here, the teachers even underscored the need to keep up with the current law as the actual syllabus of the course (for further information, see, Jensen, Nerland, and Enqvist-Jensen 2015). In the software engineering course as well, professional tools and resources were pointed out and demonstrated by the teachers during the course. The knowledge resources activated in the teacher education course were however of a more local educational nature, such as a textbook developed for educational use. Nevertheless, although given a particular local instantiation in the texts, the theories and concepts mobilised in the book relate to the wider field of learning research and are shared globally.

The examples from the introductory courses illustrate how practices and tools circulate in a profession and are approached and further explored in educational settings. To understand professional learning and, more specifically, the enrolment of newcomers in evolving professional fields, we therefore need to understand how practices and tools are embedded in distinct local and extended machineries of knowledge construction. Epistemic practices are critical to assembling and approaching such resources. Moreover, they are enacted to 'make universals from particulars' in professional problem solving, and vice versa (cf. Bueger 2015). This movement between the general and the specific between the tasks at hand and the collective ways of 'doing knowledge' in the profession - is the key to connecting practices across sites as well as to sustaining and nourishing the professional machinery of knowledge construction. Moreover, by highlighting the dynamic interplay between people, epistemic practices, knowledge resources and objects, the analytical framework allows for examining the enrolment of students in evolving practices and ways of working with knowledge in the profession. From this perspective, educational settings should be recognised not primarily as contexts for introducing students to stable knowledge but rather as one of the key knowledge settings where professional knowledge is performed and sustained. 


\section{Conclusion}

Although the examples above are limited in their empirical context and scope, they illustrate how professional education comprises dynamic knowledge settings in which knowledge and tools that are shared in the wider profession become assembled and translated for educational use through the enactment of epistemic practices. Education is from this perspective concerned with the enrolment of newcomers in professionspecific ways of handling knowledge, including ways of framing, exploring and resolving problems as profession-specific problems. The examples also illustrate that such practices take on distinct forms in distinct areas of expertise. Taking the linkages to the wider machinery into account in conceptualisations of professional education and learning is important for our understanding of what learning entails in different areas of expertise and how the demands of expertise may change over time. This calls for more extensive and multi-sited empirical research as well as for research that traces developments in knowledge practices and relations over time. This concluding section will discuss possible implications of this wider agenda when it comes to professional education and further research.

\section{Implications for professional education}

For educational programmes, the dynamic ways in which such links are set up and maintained are critical for the enrolment of new generations of students. Productive relations to knowledge settings elsewhere can be enhanced through a greater awareness of the epistemic practices that characterise professionals' work and of shared epistemic objects in the profession (see, for instance, Cunningham and Kelly 2017, for a discussion on epistemic practices in engineering and their implications for engineering education). Moreover, by making other parts of the machinery of knowledge construction transparent in specific knowledge settings, students and other actors may get an expanded understanding of their tasks and, more generally, of the field of knowledge and how it evolves. The examples above also indicate that skilful practice often requires taking the wider machinery into account, for instance, in order to assess the relevance of knowledge sources or validity claims. This becomes even more important in the context of the extended responsibilities and demands of professionals, as discussed in the introduction to this article. One way to keep knowledge dynamic and help it cater to adaptive expertise might be for the knowledge dynamics of the profession to have a bearing on the educational activities. At the same time, educational programmes would have to decompose and simplify the messiness of professional practices for learning purposes, but this does not necessarily mean that knowledge settings need to be constrained. The concepts of epistemic practices and object relations provide analytical resources for studying professional learning as embedded in local and wider knowledge dynamics and to analytically 'reunite' aspects of work and education as sites for learning. This way of thinking may also be used to guide the design of educational arrangements. Moreover, such arrangements may take into account a range of settings other than education and work, such as research environments or social media and online communities. 


\section{Methodological implications}

The suggestions presented in this article entail expanding the analytical scope of studies on professional learning to include the knowledge dynamics in which professional education and work is embedded. Analytically, it implies attending to the practices that emerge in specific knowledge settings and combining in-depth studies of the epistemic practices and object relations that unfold therein by tracing connections and linkages to practices in other settings within the wider professional culture. Drawing on the ideas of Nicolini (2009), the trailing of such connections would start in a practice setting by revealing the assemblage of knowledge, practices and resources and by moving analytically in time and space by following discursive and material connections. For instance, the knowledge resources mobilised in a specific educational setting may be derived from a practitioner community at work, from a clearing house or from research activities, and these may bring certain ways of knowing and acting to bear on the educational practice when they are enacted in situ. By combining strategies of 'zooming in' on the way the resources are approached and adapted in local practice with a 'zooming out' to the way they also connect to other settings in the wider machinery, it is possible to grasp both how educational practices are accomplished in situ and how they are embedded in the wider knowledge dynamics of a profession (Nicolini 2009). Moreover, the knowledge-generating roles of practitioners in the various sites may be explicated and acknowledged. When practitioners explore shared epistemic objects and make use of distributed resources in the local enactments of practice, they also contribute to link knowledge settings in the profession, thus affording the further circulation of knowledge across organisational boundaries (see also, Nerland and Jensen 2012).

An evident methodological challenge, then, is to delimit the scope of analysis into a feasible format. The relational way of thinking that permeates the analytical perspective suggested here, as well as network approaches more generally, makes it necessary to thoughtfully demarcate the phenomenon under investigation and to make some choices regarding what questions and relations one wants to foreground in the analysis (see also Nerland and Hermansen 2017). When practices and opportunities for learning emerge through the way people, materiality and knowledge resources of various kinds become entangled in practice, and the practices and resources are connected with other knowledge settings in the wider machinery of knowledge construction, it becomes impossible to take all relations into account in one empirical study. This article suggests foregrounding the epistemic dimension of practice and focusing on how knowledge objects are explored and transformed in situ through the enactment of epistemic practices as well as the way in which these objects and practices generate connections to other knowledge settings. This would serve as a way of seeing education and work as interrelated rather than disconnected spheres in a professional knowledge culture.

\section{Future research needs and emerging challenges}

While the perspectives and approaches suggested here may be generally helpful to trace knowledge practices and relations in professional learning, one can imagine that changes in knowledge generation and the increased complexity of professional work may generate new research needs and challenges. First, as discussed in the introduction, 
the increase in knowledge-generating actors and types of stakeholders generate multicharged knowledge settings, characterised by the simultaneous presence of multiple objectives and purposes (Knorr Cetina and Reichmann 2015). This is likely to be manifested in more complex epistemic objects and as intensified epistemic tensions on the production floor. An emerging question that needs to be researched is how then such tensions play out in educational settings and what this means for education-work relations. For instance, one could imagine that this development leads to a further specialisation and division of responsibilities in work settings. What would it mean for the opportunities to share knowledge practices and objects in educational and work settings? What are the conditions for assembling and representing professional knowledge in practices enacted by newcomers? What would still count as generalised principles and methods in the profession, and what would be seen as specific approaches developed to address specific problems?

A related question is what this development implies for the opportunities to research professional practices and their knowledge relations. Increased specialisation makes professional practices more advanced and potentially less transparent. What does this require from the researcher? Is it possible to understand professional education and learning without having a sound understanding of the types of knowledge practices and the use of specialised tools that professional work entails? One response might be to develop further models of researcher-practitioner collaborations and to recognise research as a co-production activity. This is interesting also from the point of view that the research practice itself might become a loop in the professional machinery of knowledge construction. In any case, future research on professional education and learning would benefit from instilling a variation in the use of approaches as well as in the units of analysis. No study can address everything; however, by explicating the analytical scope and by accounting for how the here-and-now is related to knowledge and practices elsewhere, we may be able to make cohesive contributions for a better understanding of the complexity of professional education and learning.

\section{Notes}

1. Calls for research that go beyond this boundary have also been raised in this journal. See, for instance, Appleby and Hillier (2012) as well as the Special Issue Vol. 37(2), edited by Bradbury et al. (2015).

2. The project Horizontal Governance and Learning Dynamics in Higher Education was financed by the Research Council of Norway (2012-2016) and was based in the Department of Education, University of Oslo.

\section{Disclosure statement}

No potential conflict of interest was reported by the author.

\section{Funding}

The empirical studies referred to were conducted as part of the project 'Horizontal Governance and Learning Dynamics in Higher Education' (2012-2016), which received financial support from the Norges Forskningsråd under the Education 2020 programme [grant number: 212285]. 


\section{ORCID}

Monika Nerland (D) http://orcid.org/0000-0003-2154-0842

\section{References}

Anagnostopoulos, D., E. R. Smith, and K. G. Basmadjian. 2007. "Bridging the University-School Divide-Horizontal Expertise and the 'Two-Worlds Pitfall'." Journal of Teacher Education 58 (2): $138-152$.

Appleby, Y., and Y. Hillier. 2012. "Exploring Practice - Research Networks for Critical Professional Learning." Studies in Continuing Education 34 (1): 31-43.

Billett, S., R. Smith, and M. Barker. 2005. "Understanding Work, Learning, and the Remaking of Cultural Practices." Studies in Continuing Education 27 (3): 219-237.

Bradbury, H., S. Kilminster, R. O’Rourke, and M. Zukas. 2015. "Professionalism and Practice: Critical Understandings of Professional Learning and Education." Studies in Continuing Education 37 (2): 125-130.

Bueger, C. 2015. "Making Things Known: Epistemic Practices, the United Nations, and the Translation of Piracy." International Political Sociology 9 (1): 1-18.

Cunningham, C., and G. Kelly. 2017. "Epistemic Practices of Engineering for Education." Science Education 101 (3): 486-505.

Damşa, C. I., and M. Nerland. 2016. "Student Learning Through Participation in Inquiry Activities: Two Case Studies in Teacher and Computer Engineering Education.” Vocations and Learning 9 (3): 275-294.

Damşa, C., M. Nerland, and K. Jensen. 2017. "Enrolment of First-Year Students in Knowledge Domains: Unpacking Transformative Practices in Three Introductory Courses." In Higher Education Transitions: Theory and Research, edited by E. Kyndt, V. Donche, K. Trigwell, and S. Lindblom-Ylänne, 270-287. London: Routledge /EARLI series "New Perspectives on Learning and Instruction".

Engeström, Y. 2004. "New Forms of Learning in Co-Configuration Work." Journal of Workplace Learning 16 (1/2): 11-21.

Engeström, Y., and A. L. Sannino. 2010. "Studies of Expansive Learning: Foundations, Findings and Future Challenges." Educational Research Review 5: 1-24.

Fenwick, T., and R. Edwards. 2013. "Networks of Knowledge, Matters of Learning, and Criticality in Higher Education.” Higher Education 67 (1): 35-50.

Fenwick, T., R. Edwards, and P. Sawchuk. 2011. Emerging Approaches to Educational Research: Tracing the Socio-Material. Abingdon: Routledge.

Hager, P., A. Lee, and A. Reich, eds. 2012. Practice, Learning and Change. Practice-Theory Perspectives on Professional Learning. Dordrecht: Springer.

Hakkarainen, K., T. Palonen, S. Paavola, and E. Lehtinen. 2004. Communities of Networked Expertise: Professional and Educational Perspectives. Oxford: Elsevier.

Jensen, K., M. Nerland, and C. Enqvist-Jensen. 2015. "Enrolment of Newcomers in Expert Cultures: An Analysis of Epistemic Practices in a Legal Education Introductory Course." Higher Education 70 (5): 867-880.

Kelly, G. J. 2011. "Scientific Literacy, Discourse and Epistemic Practices." In Exploring the Landscape of Scientific Literacy, edited by P. O. Wickman, L. Östman, D. A. Roberts, G. Erickson, and A. MacKinnon, 61-73. New York: Routledge.

Knorr Cetina, K. 1999. Epistemic Cultures: How the Sciences Make Knowledge. Cambridge: Harvard University Press.

Knorr Cetina, K. 2001. “Objectual Practice.” In The Practice Turn in Contemporary Theory, edited by T. R. Schatzki, K. Knorr Cetina, and E. Von Savigny, 175-188. London: Routledge.

Knorr Cetina, K. 2007. "Culture in Global Knowledge Societies: Knowledge Cultures and Epistemic Cultures.” Interdisciplinary Science Reviews 32 (4): 361-375. 
Knorr Cetina, K., and W. Reichmann. 2015. "Professional Epistemic Cultures.” In Epistemic and Learning Cultures-woher und wohin sich Universitäten entwickeln, edited by I. Langemeyer, M. Fischer, and M. Pfadenhauer, 18-33. Weinheim: Juventa Verlag.

Lahn, L., and K. Jensen. 2006. "Models of Professional Learning. Exploring the Epistemic Tool Perspective." Knowledge, Work and Society 4 (3): 63-82.

Lave, J. 1993. "The Practice of Learning." In Understanding Practice: Perspectives on Activity and Context, edited by S. Chaiklin and J. Lave, 3-32. Cambridge: Cambridge University Press.

Lave, J., and E. Wenger. 1991. Situated Learning: Legitimate Peripheral Participation. Cambridge: Cambridge University Press.

Ludvigsen, S. R., and M. Nerland. 2014. "Knowledge Sharing in Professions: Working Creatively with Standards in Local Settings." In Learning and Collective Creativity. Activity-Theoretical and Sociocultural Studies, edited by A. Sannino and V. T. Ellis, 116-131. London: Routledge.

Malcolm, I. 2014. "The Future of Digital Working: Knowledge Migration and Learning." Learning, Media and Technology 39 (4): 449-467.

Markauskaite, L., and P. Goodyear. 2016. Epistemic Fluency and Professional Education. Innovation, Knowledgeable Action and Actionable Knowledge. Singapore: Springer.

Nerland, M., and C. I. Damsa. in press. "VET as Lifelong Learning: Engagement with Distributed Knowledge in Software Engineering." Forthcoming. In The Wiley Handbook of Vocational Education and Training, edited by L. Unwin and D. Guile. London: Wiley-Blackwell.

Nerland, M., and H. Y. Hermansen. 2017. "Sosiomaterielle perspektiver på profesjonskvalifisering: Kunnskapsressursenes betydning [Sociomaterial Perspectives on Qualifying Professional Practitioners: The Significance of Knowledge Resources].” In Kvalifisering til profesjonell yrkesutøvelse, edited by S. Mausethagen and J.-C. Smeby, 167-179. Oslo: Universitetsforlaget.

Nerland, M., and K. Jensen. 2012. "Epistemic Practices and Object Relations in Professional Work." Journal of Education and Work 25 (1): 101-120.

Nerland, M., and K. Jensen. 2014a. "Changing Cultures of Knowledge and Professional Learning." In International Handbook of Research in Professional and Practice-Based Learning, edited by S. Billett, C. Harteis, and H. Gruber, 611-640. Dordrecht: Springer.

Nerland, M., and K. Jensen. 2014b. "Learning Through Epistemic Practices in Professional Work: Examples from Nursing and Computer Engineering." In Reconceptualizing Professional Learning, edited by T. Fenwick and M. Nerland, 25-37. London: Routledge.

Nespor, J. 1994. Knowledge in Motion: Space, Time and Curriculum in Undergraduate Physics and Management. London: RoutledgeFalmer.

Nicolini, D. 2009. "Zooming In and Out: Studying Practices by Switching Theoretical Lenses and Trailing Connections." Organization Studies 30 (12): 1391-1418.

Nicolini, D., B. E. Mørk, J. Masovic, and O. Hanseth. 2017. "Expertise as Trans-Situated. The Case of TAVI." In Skillful Performance: Enacting Capabilities, Knowledge, Competence, and Expertise in Organizations, edited by J. Sandberg, L. Rouleau, A. Langley, and H. Tsoukas, 27-49. Oxford: Oxford University Press.

Säljö, R. 2010. “Learning in a Sociocultural Perspective." In International Encyclopedia of Education. 3rd ed. edited by P. Peterson, E. Baker, and B. McGaw, 498-502. Oxford: Elsevier. 